\title{
Daphnetin Preconditioning Decreases Cardiac Injury and Susceptibility to Ventricular Arrhythmia following Ischaemia-Reperfusion through the TLR4/MyD88/NF-Kb Signalling Pathway
}

\author{
Fan Yang $^{\mathrm{a}}$ Xiaobo Jiang ${ }^{\mathrm{a}}$ Hongyi Cao $^{\mathrm{b}}$ Wei Shuai ${ }^{\mathrm{a}}$ Lijun Zhang $^{\mathrm{c}}$ \\ Guangji Wang $^{\text {a }}$ Dajun Quan $^{a}$ Xuejun Jiang ${ }^{a}$ \\ aDepartment of Cardiology, Renmin Hospital of Wuhan University, Cardiovascular Research Institute of

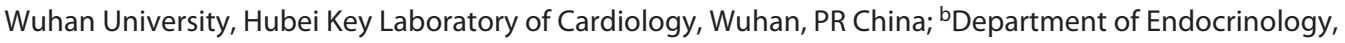 \\ Chengdu Fifth People's Hospital, Chengdu, PR China; 'Department of Geriatrics, Renmin Hospital of \\ Wuhan University, Wuhan, PR China
}

\section{Keywords}

Ischaemia-reperfusion injury · Daphnetin · Arrhythmia · Toll-like receptor 4 signalling pathway $\cdot$ Inflammation . Oxidative stress

\begin{abstract}
Background/Aims: Daphnetin (7,8-dihydroxycoumarin, DAP) exhibits various bioactivities, such as anti-inflammatory and antioxidant activities. However, the role of DAP in myocardial ischaemia/reperfusion (I/R) injury and I/R-related arrhythmia is still uncertain. This study aimed to investigate the mechanisms underlying the effects of DAP on myocardial I/R injury and electrophysiological properties in vivo and in vitro. Methods: Myocardial infarct size was measured by triphenyltetrazolium chloride staining. Cardiac function was assessed by echocardiographic and haemodynamic analyses. The levels of creatine kinase-MB, lactate dehydrogenase, malondialdehyde, superoxide dismutase, interleukin-6 (IL6), and tumour necrosis factor-alpha (TNF-a) were detected
\end{abstract}

karger@karger.com www.karger.com/pha

Karger $\stackrel{\text { ' }}{5}$

BOPEN ACCESS
(C) 2021 The Author(s)

Published by S. Karger AG, Basel

This is an Open Access article licensed under the Creative Commons Attribution-NonCommercial-4.0 International License (CC BY-NC) (http://www.karger.com/Services/OpenAccessLicense), applicable to the online version of the article only. Usage and distribution for commercial purposes requires written permission. using commercial kits. Apoptosis was measured by terminal deoxynucleotidyl-transferase-mediated dUTP nick-end labelling staining and flow cytometry. The viability of $\mathrm{H} 9 \mathrm{c} 2$ cells was determined by the Cell Counting Kit- 8 assay. In vitro, the levels of IL- 6 and TNF- $a$ were measured by quantitative PCR. The expression levels of proteins associated with apoptosis, inflammation, and the Toll-like receptor $4 / m y-$ eloid differentiation factor 88/nuclear factor kappa B (TLR4/ MyD88/NF-KB) signalling pathway were detected by Western blot analysis. The RR, PR, QRS, and QTc intervals were assessed by surface ECG. The $90 \%$ action potential duration $\left(\mathrm{APD}_{90}\right)$, threshold of APD alternans, and ventricular tachycardia inducibility were measured by the Langendorff perfusion technique. Results: DAP preconditioning decreased myocardial I/R injury and hypoxia/reoxygenation (H/R) injury in cells. DAP preconditioning improved cardiac function after myocardial I/R injury. DAP preconditioning also sup-

Fan Yang and Xiaobo Jiang contributed equally to this work.
Correspondence to:

Xuejun Jiang, xjjiang@whu.edu.cn 
pressed apoptosis, attenuated oxidative stress, and inhibited inflammatory responses in vivo and in vitro. Furthermore, DAP preconditioning decreased the susceptibility to ventricular arrhythmia after myocardial I/R. Finally, DAP preconditioning inhibited the expression of TLR4, MyD88, and phosphorylated NF-KB (p-NF-KB)/P65 in mice subjected to I/R and cells subjected to $H / R$. Conclusions: DAP preconditioning protected against myocardial I/R injury and decreased susceptibility to ventricular arrhythmia by inhibiting the TLR4/ MyD88/NF-kB signalling pathway. @ 2021 The Author(s)

Published by S. Karger AG, Basel

\section{Introduction}

Cardiovascular disease remains the leading cause of mortality and morbidity in populations around the world [1]. Myocardial ischaemia/reperfusion (I/R) injury is a clinically relevant problem that is associated with thrombolytic therapy, percutaneous transluminal coronary angioplasty, coronary artery bypass grafting, and heart transplantation, and myocardial I/R injury is a phenomenon in which reperfusion itself exacerbates myocardial injury and reduces cardiac function [2-4]. Previous studies have shown that many mechanisms are involved in myocardial I/R injury, including oxidative stress, calcium overload, inflammatory responses, and apoptosis $[5,6]$. Thus, the regulation of these pathological mechanisms is important for prevention of myocardial I/R injury [7, 8].

Daphnetin (7,8-dihydroxycoumarin, DAP) is a coumarin derivative extracted from Daphne koreana (D. koreana) Nakai. Many studies have shown that DAP exhibits broad pharmacological effects, including anti-inflammatory, antioxidative, and antithrombotic activities [9-12]. Additionally, a recent study revealed that DAP protects against cerebral I/R injury in mice via inhibiting inflammation and apoptosis [13]. However, there have been few studies on the cardioprotective effect of DAP. Thus, the present study was designed to investigate the effect of DAP and its underlying mechanisms in an in vivo model of $\mathrm{I} / \mathrm{R}$ and an in vitro model of hypoxia/reoxygenation $(\mathrm{H} / \mathrm{R})$.

\section{Materials and Methods}

Animals

All animal and study protocols were approved by the Ethics Committee of Renmin Hospital of Wuhan University (IACUC No. 20171224) and conducted in accordance with the Guide for the Care and Use of Laboratory Animals published by the US Nation- al Institutes of Health (Publication No. 85-23, revised 1996). All mice used in the studies were male and 8 to 12 weeks old. All mice were maintained in an environment with constant temperature under a 12-h light/12-h dark cycle and were provided water and food ad libitum. Animal health and behaviour were monitored twice a day.

\section{Myocardial I/R Model}

The mice were anaesthetized using $50 \mathrm{mg} / \mathrm{kg}$ pentobarbital sodium by intraperitoneal injection. The anaesthetized mice were intubated with a PE-90 catheter and ventilated with normal $\mathrm{PO}_{2}$, $\mathrm{PCO}_{2}$, and $\mathrm{pH}$ using a rodent ventilator. Body temperature was maintained at $37 \pm 0.5^{\circ} \mathrm{C}$ with a homeothermic blanket. After left thoracotomy was performed, the left anterior descending coronary artery (LAD) was exposed. Ischaemia was performed with an 8-0 silk ligature that was placed around the LAD and a piece of PE-10 tubing that was placed over the LAD. After occlusion for $45 \mathrm{~min}$, reperfusion was achieved by releasing the ligature and removing the PE-10 tubing. The air was expelled from the thoracic cavity, and the chest wall was closed. Sham-operated mice underwent the same surgical procedures without LAD ligation and reperfusion.

\section{Experimental Groups}

To determine the optimal dose of DAP (MedChemExpress, Monmouth Junction, NJ, USA; HY-N0281), the mice were randomly assigned into 6 groups: the sham group $(n=13), \mathrm{I} / \mathrm{R}$ group $(n=14), \mathrm{I} / \mathrm{R}+\mathrm{DAP}(2.5 \mathrm{mg} / \mathrm{kg})$ group $(n=14), \mathrm{I} / \mathrm{R}+\mathrm{DAP}(5 \mathrm{mg} /$ $\mathrm{kg})$ group $(n=14), \mathrm{I} / \mathrm{R}+\mathrm{DAP}(10 \mathrm{mg} / \mathrm{kg})$ group $(n=14)$, and $\mathrm{I} / \mathrm{R}$ + DAP $(20 \mathrm{mg} / \mathrm{kg})$ group $(n=14)$ (Fig. 1a). Based on the myocardial infarct size and the levels of myocardial injury markers, the 10 $\mathrm{mg} / \mathrm{kg}$ dose was determined to be the optimal dose and was used in the following experiment. For the subsequent experiment, the mice were randomly divided into 4 groups: the sham group $(n=$ $35)$, sham + DAP $(10 \mathrm{mg} / \mathrm{kg})$ group $(n=35), \mathrm{I} / \mathrm{R}$ group $(n=37)$, and $\mathrm{I} / \mathrm{R}+\mathrm{DAP}(10 \mathrm{mg} / \mathrm{kg})$ group $(n=37)$ (Fig. $1 \mathrm{~b})$. In the DAPtreated groups, DAP was diluted in $0.9 \%$ saline and administered via daily gavage for 2 days before sham operation or I/R operation. An equal volume of $0.9 \%$ saline was administered in the DAPuntreated group. For long-term follow-up, the mice in the DAP treatment groups were treated with $10 \mathrm{mg} / \mathrm{kg}$ by daily gavage. In total, 227 mice were used for the experiment.

\section{Infarct Size Determination}

Infarct size was assessed by triphenyltetrazolium chloride (TTC; Sigma-Aldrich, Merck KGaA) staining as described previously [14]. Briefly, the LAD was retied, and 2\% Evans blue was injected into the jugular vein to demarcate the non-perfused myocardium from the perfused myocardium after $24 \mathrm{~h}$ of reperfusion. The heart was removed and frozen at $-20^{\circ} \mathrm{C}$ for $15 \mathrm{~min}$. The frozen heart was sliced into 5 sections from the apex to the base and further incubated in $2 \%$ TTC at $37^{\circ} \mathrm{C}$ for $15 \mathrm{~min}$ to visualize the infarct area. Finally, the sections were fixed in $4 \%$ paraformaldehyde solution for $24 \mathrm{~h}$ and measured using Image-Pro Plus software (version $6.0)$.

Echocardiography and Haemodynamic Measurements

Before and $24 \mathrm{~h}$, and 7 and 28 days after sham or I/R surgery, mice treated with DAP $(10 \mathrm{mg} / \mathrm{kg})$ and untreated mice underwent transthoracic echocardiographic examination. Briefly, echocar- 


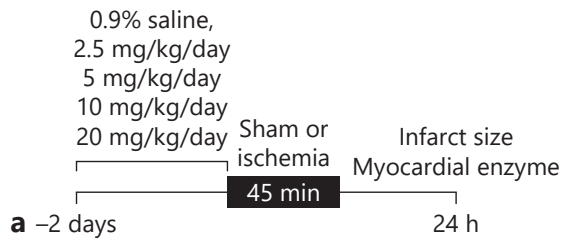

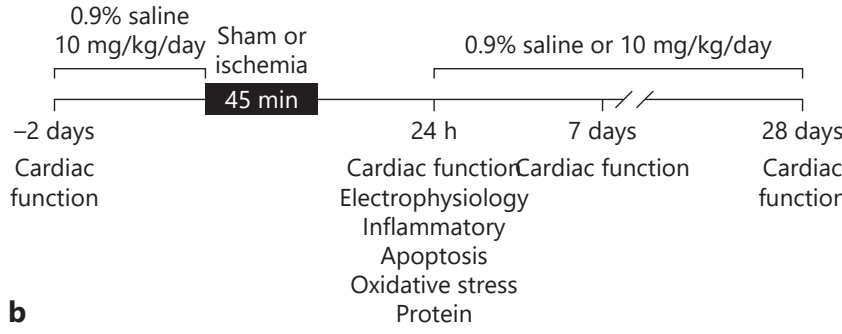
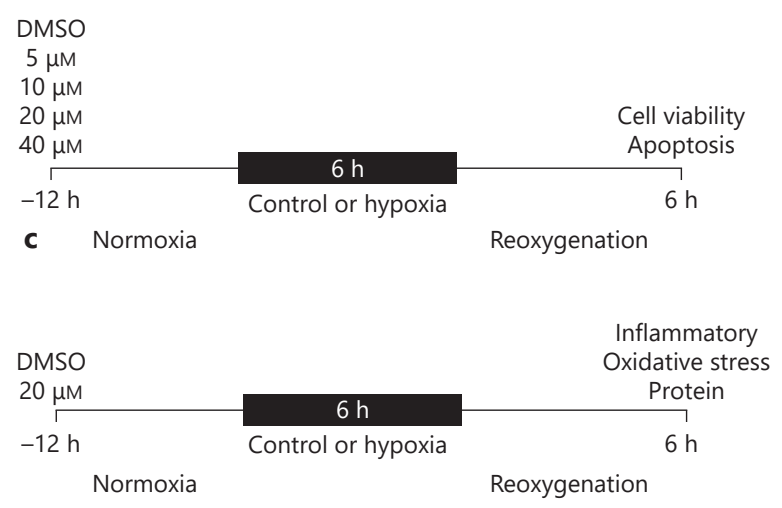

d
Fig. 1. Experimental protocol. a Different concentrations $(2.5,5$, 10 , and $20 \mathrm{mg} / \mathrm{kg}$ ) of DAP and an equal volume of $0.9 \%$ saline were administered via daily gavage for 2 days before sham operation or I/R operation, and the myocardial infarct size and the myocardial enzyme levels were assessed $24 \mathrm{~h}$ after sham or I/R surgery. b DAP $(10 \mathrm{mg} / \mathrm{kg})$ and an equal volume of $0.9 \%$ saline were administered via daily gavage for 2 days before sham operation or I/R operation and for the long-term follow-up (treatment starting $24 \mathrm{~h}$ after sham or I/R operation). Electrophysiology, inflammation, apoptosis, oxidative stress, and protein expression were evaluated $24 \mathrm{~h}$ after sham or I/R surgery. Cardiac function was assessed before

diography was performed under anaesthesia (1.5-2\% isoflurane) using the Mylab30CV (Biosound Esaote Inc.) ultrasound system equipped with a $15-\mathrm{MHz}$ probe. $\mathrm{M}$-mode tracings at the papillary muscle level were recorded to acquire the following parameters: left ventricle (LV) ejection fraction (EF) and LV fractional shortening (FS) $[14,15]$. Twenty-eight days after sham or I/R surgery, haemodynamic parameters were measured in mice treated with DAP $(10 \mathrm{mg} / \mathrm{kg})$ and untreated mice. A Millar catheter-tip micromanometer (SPR-839; Millar Instruments) was inserted into the LV from the right carotid artery. After stabilization for $15 \mathrm{~min}$, the ARIA pressure-volume conductance system coupled with a PowerLab/4SP A/D converter was used to continuously record the left ventricular minimum and maximum rates of pressure increase (dp/dt min and dp/dt max, respectively) [14].

\section{Immunofluorescence Analysis}

The hearts of mice treated with DAP $(10 \mathrm{mg} / \mathrm{kg})$ and untreated mice $24 \mathrm{~h}$ after sham or I/R surgery were harvested, fixed in $4 \%$ paraformaldehyde solution for $24 \mathrm{~h}$, embedded in paraffin, and then cut into 5- $\mu \mathrm{m}$ sections. After dewaxing and antigen retrieval, the slices were incubated with an LY6G antibody (BD Biosciences, Franklin Lakes, NJ, USA) overnight at $4^{\circ} \mathrm{C}$ and then incubated with a rhodamine (TRITC)-conjugated goat anti-rat IgG secondary antibody (Proteintech Group, Chicago, USA) for $50 \mathrm{~min}$ at $37^{\circ} \mathrm{C}$. Finally, the nuclei were stained with $4^{\prime}, 6^{\prime}$-diamidino-2-phe- and $24 \mathrm{~h}$, and 7 and 28 days after sham or I/R operation. c H9c2 cells were pretreated with different concentrations $(5,10,20$, and $40 \mu \mathrm{M}$ ) of DAP and $0.01 \%$ DMSO for $12 \mathrm{~h}$ and then subjected to 6 $\mathrm{h}$ of hypoxia and $6 \mathrm{~h}$ of reoxygenation or control treatment. Cell viability and apoptosis were tested in the $\mathrm{H} / \mathrm{R}$ and control groups. d $\mathrm{H} 9 \mathrm{c} 2$ cells were pretreated with DAP $(20 \mu \mathrm{M})$ and $0.01 \%$ DMSO for $12 \mathrm{~h}$ and then subjected to $6 \mathrm{~h}$ of hypoxia and $6 \mathrm{~h}$ of reoxygenation or control treatment. Inflammation, oxidative stress, and protein expression were tested in the $H / R$ and control groups. I/R, ischaemia/reperfusion; $\mathrm{H} / \mathrm{R}$, hypoxia/reoxygenation; DMSO, dimethylsulphoxide.

nylindole (ASPEN Biotechnology Co., Ltd., Wuhan, China) at room temperature for $5 \mathrm{~min}$. Each section was observed with fluorescence microscopy.

\section{TUNEL Assays}

Myocardial apoptosis was detected by the terminal deoxynucleotidyl transferase-mediated dUTP nick-end labelling (TUNEL) technique. Heart tissue sections, which were prepared as for immunofluorescence, were stained using a TUNEL kit (Roche Diagnostics, Basel, Switzerland). The nuclei of apoptotic cells were stained green, and total nuclei were stained blue. The extent of cell apoptosis is presented as the percentage of apoptotic nuclei relative to total nuclei.

\section{Cell Culture and H/R Model Establishment}

H9c2 cells (iCell Bioscience Inc., Shanghai, China) were cultured in Dulbecco's modified Eagle's medium (DMEM; HyClone; GE Healthcare Life Sciences, Logan, UT, USA) supplemented with $10 \%$ foetal bovine serum at $37^{\circ} \mathrm{C}$ in a humidified atmosphere containing $5 \% \mathrm{CO}_{2}$. In the preliminary experiments, the cells were divided into 6 groups: the control group, H/R group, H/R + DAP $(5 \mu \mathrm{M})$ group, $\mathrm{H} / \mathrm{R}+\mathrm{DAP}(10 \mu \mathrm{M})$ group, $\mathrm{H} / \mathrm{R}+\mathrm{DAP}(20 \mu \mathrm{M})$ group, and H/R + DAP $(40 \mu \mathrm{M})$ group (Fig. 1c). Based on the results of the Cell Counting Kit-8 (CCK-8) assay and flow cytometry, the cells were divided into 4 groups: the control group, control + 


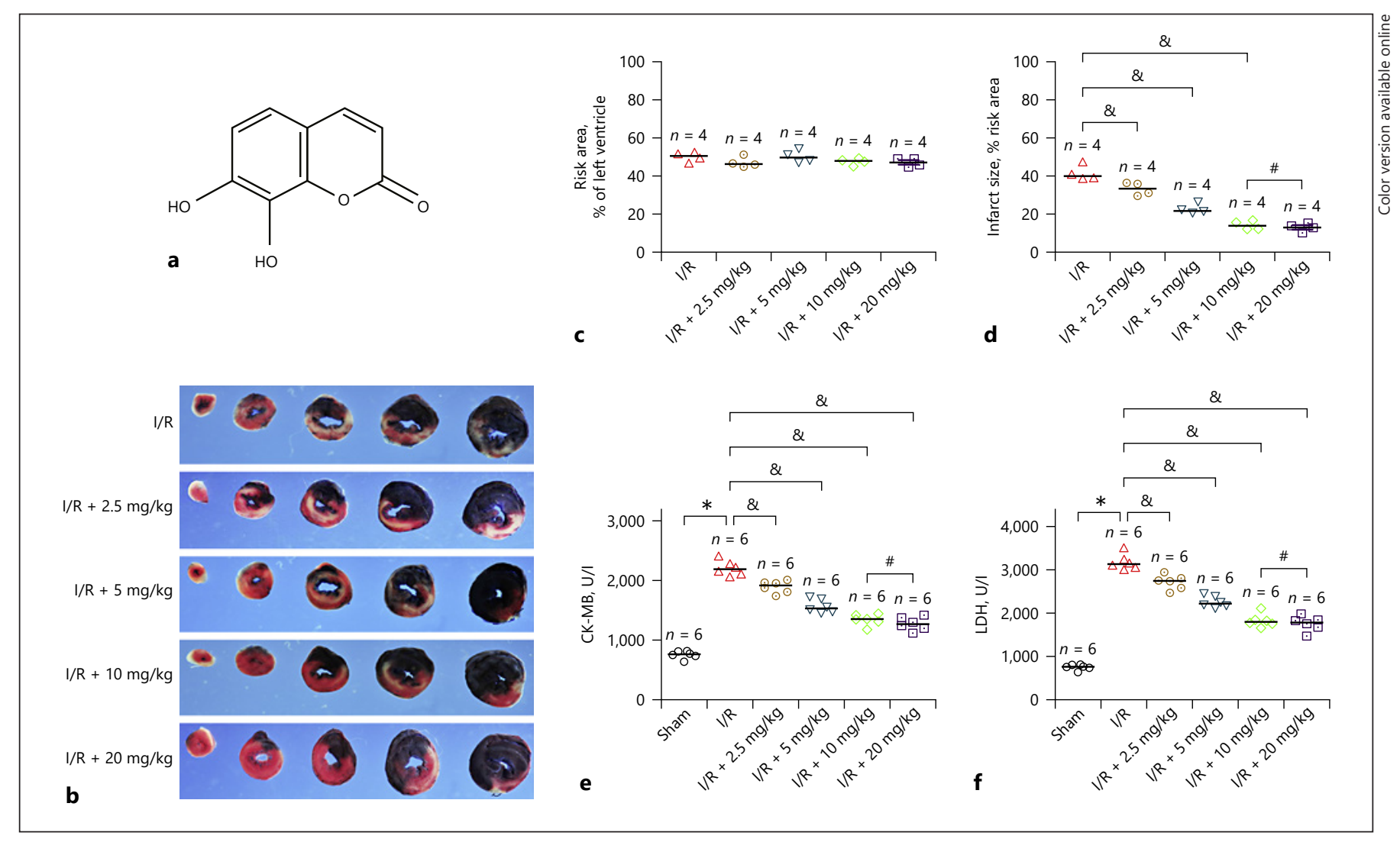

Fig. 2. a The chemical structure of DAP. b Representative images of heart tissue stained with Evans blue and TTC. The blue areas indicate non-ischaemic/perfused tissue. The red plus white areas, which are the risk areas, indicate ischaemic myocardium. The red areas indicate ischaemic but viable tissue. The white areas indicate infarcted tissue. c, d Scatter dot plots quantifying the risk area as a percentage of the LV area and infarct size as a percentage of the

DAP $(20 \mu \mathrm{M})$ group, H/R group, and H/R + DAP (20 $\mu \mathrm{M})$ group (Fig. 1d). For hypoxia, the cells were maintained in an incubator with $1 \% \mathrm{O}_{2}, 5 \% \mathrm{CO}_{2}$, and $94 \% \mathrm{~N}_{2}$ at $37^{\circ} \mathrm{C}$ for $6 \mathrm{~h}$. For reoxygenation, the cells were incubated in a humidified atmosphere with $95 \%$ air and $5 \% \mathrm{CO}_{2}$ at $37^{\circ} \mathrm{C}$ for $6 \mathrm{~h}$. Control cells were maintained in $95 \%$ air and $5 \% \mathrm{CO}_{2}$ at $37^{\circ} \mathrm{C}$. In the DAP groups, the cells were pretreated with DAP for $12 \mathrm{~h}$ and then subjected to H/R or control treatment. In the DAP-untreated groups, the cells were pretreated with $0.01 \%$ dimethylsulphoxide.

\section{CCK-8 Assay}

Cell viability was determined using the CCK-8 assay (Beyotime Institute of Biotechnology, Shanghai, China) according to the manufacturer's protocol. Briefly, cells were cultured in a 96-well plate and treated as previously described. Then, $10 \mu \mathrm{L}$ of the CCK- 8 solution was added to each well, and the cells were incubated for an additional $2 \mathrm{~h}$ at $37^{\circ} \mathrm{C}$. The optical density (OD) values were measured at $450 \mathrm{~nm}$ using a microplate reader. The cell survival rate was calculated based on the following formula: cell survival rate $(\%)=($ OD experiment - OD blank $) /($ OD control - OD blank $) \times 100 \%$. risk area in $\mathrm{I} / \mathrm{R}$ and $\mathrm{I} / \mathrm{R}+\mathrm{DAP}$ mice $(n=4)$. e, $\mathbf{f}$ Scatter dot plots showing the quantification of CK-MB and LDH levels in the serum of mice $(n=6) .{ }^{*} p<0.05$ versus the sham group; ${ }^{*} p<0.05$ versus the I/R group; ${ }^{\#} p>0.05$ between the $10 \mathrm{mg} / \mathrm{kg}$ and $20 \mathrm{mg} / \mathrm{kg}$ DAP treatment groups. DAP, daphnetin; $\mathrm{CK}-\mathrm{MB}$, creatine kinase-MB; $\mathrm{LDH}$, lactate dehydrogenase; I/R, ischaemia/reperfusion; LV, left ventricle.

\section{Flow Cytometry}

Cell apoptosis was detected using an annexin V-fluorescein isothiocyanate (FITC) apoptosis detection kit according to the manufacturer's protocol (Tianjin Sungene Biotech Co., Ltd., Tianjin, China). Briefly, the cells were digested with trypsin without EDTA and centrifuged at $300 \mathrm{~g}$ for $5 \mathrm{~min}$ at $4^{\circ} \mathrm{C}$. After washing twice with PBS, the cells were suspended in $300 \mu \mathrm{L}$ of binding buffer. Then, $5 \mu \mathrm{L}$ of Annexin V-FITC and $5 \mu \mathrm{L}$ of propidium iodide were added to the cells and incubated for $10 \mathrm{~min}$ in the dark. Finally, cell apoptosis was analysed by flow cytometry (BD Biosciences, Franklin Lakes, NJ, USA).

\section{Biochemical Analysis}

Blood was harvested $24 \mathrm{~h}$ after sham or I/R surgery. The serum was isolated by centrifugation at $1,008 \times \mathrm{g}$ for $30 \mathrm{~min}$ at $4^{\circ} \mathrm{C}$ and stored at $-80^{\circ} \mathrm{C}$ until analysis. $\mathrm{H} 9 \mathrm{c} 2$ cells treated with DAP (20 $\mu \mathrm{M})$, untreated $\mathrm{H} 9 \mathrm{c} 2$ cells from the $\mathrm{H} / \mathrm{R}$ and control groups were collected and centrifuged at $2,000 \times \mathrm{g}$ for $10 \mathrm{~min}$ at $4^{\circ} \mathrm{C}$, and then the supernatants were harvested. The creatine kinase-MB (CK$\mathrm{MB})$, lactate dehydrogenase (LDH), malondialdehyde (MDA), 


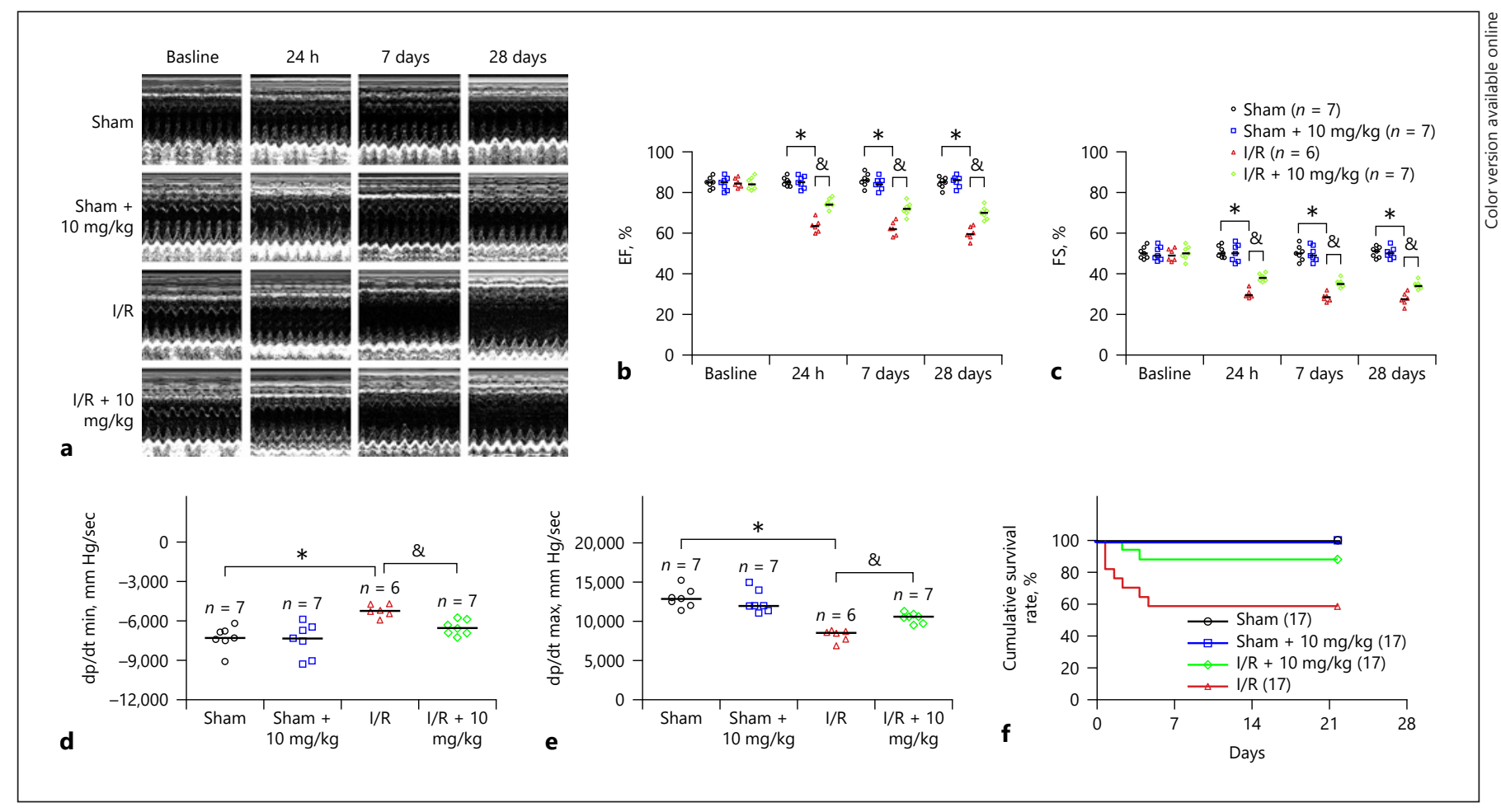

Fig. 3. a Representative M-mode images of mouse hearts. b, c Scatter dot plots showing quantification of the LV EF and LV FS before treatment and $24 \mathrm{~h}$, and 7 and 28 days after I/R $(n=6-7)$. d, e Scatter dot plots showing quantification of the minimum and maximum rates of pressure increase until 28 days $(n=6-7)$. f Kaplan-Meier plot showing the 28 -day survival rate. ${ }^{*} p<0.05$ versus the sham group; ${ }^{\circledR} p<0.05$ versus the I/R group. LV, left ventricle; EF, ejection fraction; FS, fractional shortening; I/R, ischaemia/reperfusion. and superoxide dismutase (SOD) levels were detected using commercial kits (Nanjing Jiancheng Bioengineering Institute, Nanjing, China) following the manufacturer's instructions. The levels of interleukin-6 (IL-6) and tumour necrosis factor-alpha (TNF- $\alpha$ ) were measured using commercial ELISA kits (NeoBioscience, Shenzhen, China) according to the manufacturer's protocols.

\section{Quantitative Real-Time PCR}

Total RNA was isolated from H9c2 cells treated with DAP (20 $\mu \mathrm{M})$ and from untreated H9c2 cells from the H/R and control groups using TRIpure reagent (ELK Biotechnology Co., Ltd., Wuhan, China). Then, cDNA was synthesized using the EntiLink ${ }^{\mathrm{TM}}$ First Strand cDNA Synthesis Kit (ELK Biotechnology Co., Ltd., Wuhan, China) under the following conditions: $70^{\circ} \mathrm{C}$ for $5 \mathrm{~min}$, $37^{\circ} \mathrm{C}$ for $60 \mathrm{~min}$, and $85^{\circ} \mathrm{C}$ for $5 \mathrm{~min}$. Finally, PCR amplification was carried out using EnTurbo ${ }^{\mathrm{TM}}$ SYBR Green PCR SuperMix (ELK Biotechnology Co., Ltd., Wuhan, China) under the following conditions: $95^{\circ} \mathrm{C}$ for $3 \mathrm{~min}$ followed by 40 cycles of $95^{\circ} \mathrm{C}$ for $10 \mathrm{~s}$, $58^{\circ} \mathrm{C}$ for $30 \mathrm{~s}$, and $72^{\circ} \mathrm{C}$ for $30 \mathrm{~s}$. The levels of TNF- $\alpha$ and IL- 6 were calculated using the $2^{-\Delta \Delta C T}$ method. The following primers were used for PCR analysis: GAPDH forward, 5'-CGCTAACATCAAATGGGGTG- $3^{\prime}$ and reverse, $5^{\prime}$-TTGCTGACAATCTTGAGGGAG-3'; TNF-a forward, 5'-CACCACGCTCTTCTGTCTACTG-3' and reverse, $5^{\prime}$-GCTACGGGCTTGTCACTCG-3'; and IL-6 forward, 5'-TGGAGTTCCGTTTCTACCTGG-3' and re-

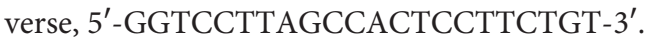

Daphnetin Decreases Myocardial I/R Injury and Susceptibility to Arrhythmia

\section{Western Blot Analysis}

Total protein was extracted from the LV tissues of mice treated with DAP $(10 \mathrm{mg} / \mathrm{kg})$ and untreated mice $24 \mathrm{~h}$ after sham or I/R surgery and from H9c2 cells treated with DAP $(20 \mu \mathrm{M})$ and untreated $\mathrm{H} 9 \mathrm{c} 2$ cells from the $\mathrm{H} / \mathrm{R}$ and control groups. The protein concentrations were measured by the BCA assay. An equal amount of protein was separated by SDS-PAGE and transferred to PVDF membranes (Millipore). The membranes were blocked with $5 \%$ non-fat milk for $1 \mathrm{~h}$ at room temperature and incubated at $4^{\circ} \mathrm{C}$ overnight with the following primary antibodies: intercellular adhesion molecule-1 (ICAM-1; 1:1,000, Proteintech Group, 100201-AP), vascular cell adhesion molecule-1 (VCAM-1; 1:2,000, Abcam, ab134047), Bax (1:1,000, CST, \#2772), cleaved caspase-3 (1:1,000, Abcam, ab49822), Bcl2 (1:2,000, Abcam, ab59348), Tolllike receptor 4 (TLR4; 1:1,000, Affbiotech, AF7017), myeloid differentiation factor 88 (MyD88; 1:1,000, CST, \#4283), p-NF- $\kappa B / P 65$ (1:1,000, CST, \#3033), and NF-кB/P65 (1:3,000, Abcam, ab16502). The blots against GAPDH were used for loading controls. The protein bands were detected by enhanced chemiluminescence (ASPEN Biotechnology Co., Ltd., Wuhan, China) and then quantified with image analysis software.

\section{Surface ECG Recording}

Twenty-four hours after sham or I/R surgery, the mice treated with DAP $(10 \mathrm{mg} / \mathrm{kg})$ and untreated mice were anaesthetized with pentobarbital sodium. Then, electrodes were placed subcutane- 

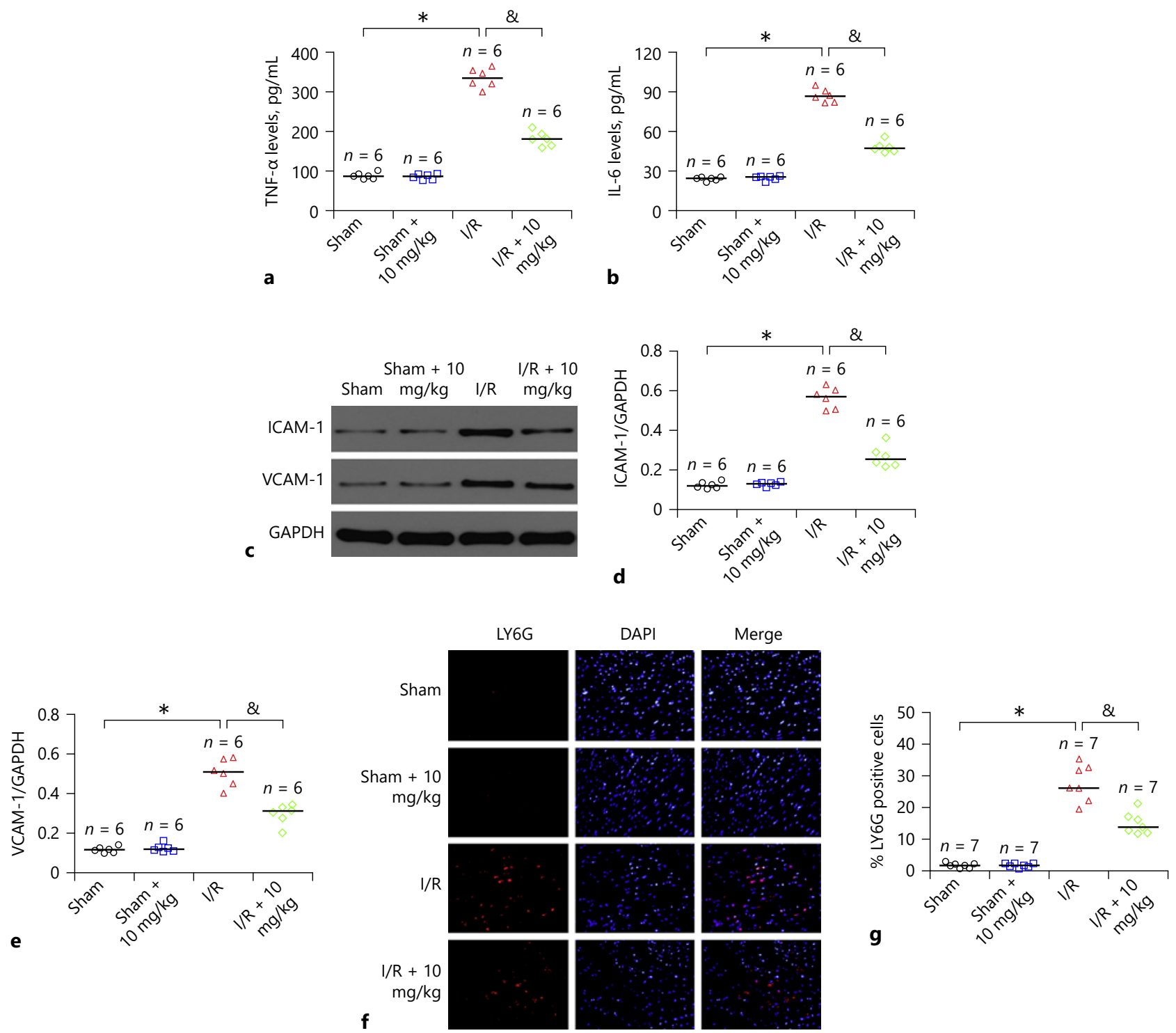

Fig. 4. a, b Scatter dot plots showing quantification of the levels of TNF- $\alpha$ and IL- 6 in the serum $(n=6)$. Representative Western blots (c) and scatter dot plots showing quantification of ICAM-1 and VCAM-1 expression in mouse hearts $(\mathbf{d}, \mathbf{e})(n=6)$. Representative immunofluorescence staining and scatter dot plots showing quan-

ously, and surface lead ECG (lead II) recordings were acquired for 10-15 min. To correct for heart rate, the QTc interval was calculated with the modified Bazett's formula $\left(\mathrm{QTc}=\mathrm{QT} /(\mathrm{RR} / 100)^{1 / 2}\right.$. The data were analysed with LabChart 7 software (AD instrument).

tification $(\mathbf{f}, \mathbf{g})$ of neutrophils $(n=7) .{ }^{*} p<0.05$ versus the sham group; ${ }^{\circledR} p<0.05$ versus the I/R group; IL-6, interleukin-6; TNF- $\alpha$, tumour necrosis factor-alpha; ICAM-1, intercellular adhesion molecule-1; VCAM-1, vascular cell adhesion molecule-1; I/R, ischaemia/reperfusion.

\section{Monophasic Action Potential Recording and Cardiac} Arrhythmia Inducibility

The mice treated with DAP $(10 \mathrm{mg} / \mathrm{kg})$ and untreated mice were anaesthetized with pentobarbital sodium $24 \mathrm{~h}$ after sham or I/R surgery and heparinized with heparin sodium. Then, the heart was removed and promptly perfused with Tyrode's solution (in mmol/L: $1 \mathrm{MgCl}_{2} ; 5.4 \mathrm{KCl} ; 1.8 \mathrm{CaCl}_{2} ; 135 \mathrm{NaCl} ; 0.3 \mathrm{Na}_{2} \mathrm{HPO}_{4} ; 10$ 
Fig. 5. a, b Scatter dot plots showing quantification of the MDA level and SOD activity in serum $(n=6) .{ }^{*} p<0.05$ versus the sham group; ${ }^{\circledR} p<0.05$ versus the I/R group. MDA, malondialdehyde; SOD, superoxide dismutase; $\mathrm{I} / \mathrm{R}$, ischaemia/reperfusion.

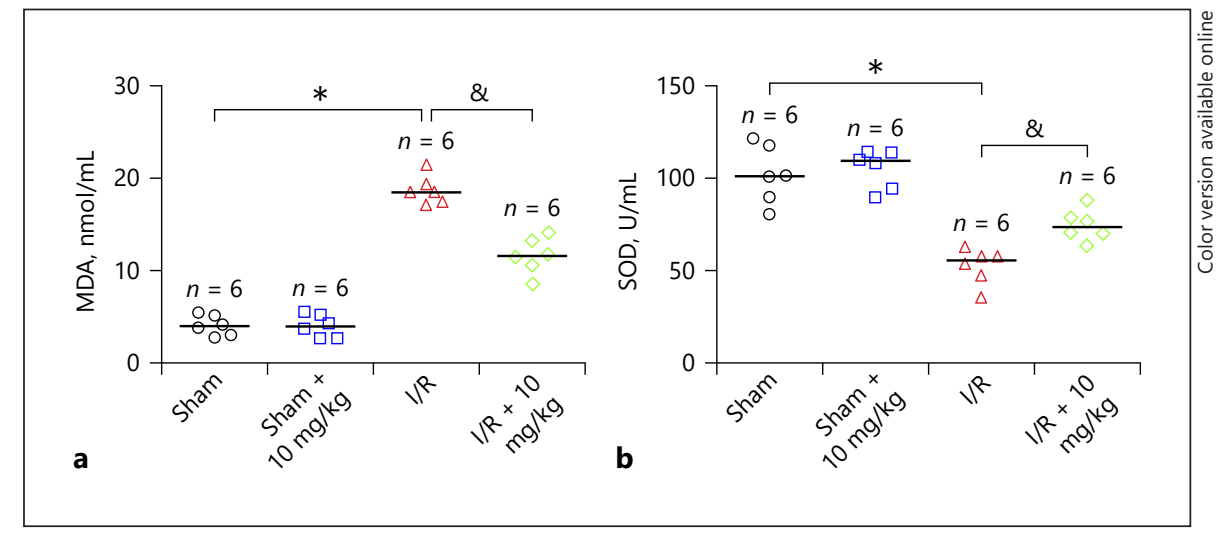

glucose; and 10 HEPES; pH 7.4) by the Langendorff method. After perfusion for $20 \mathrm{~min}$ at $37^{\circ} \mathrm{C}$, the pacing electrode was placed on the basal surface of the right ventricle. The recording electrode was positioned on the peri-infarct zone of LV. A pacing cycle length (PCL) of $150 \mathrm{~ms}$ was used to record the monophasic action potential (MAP). The $90 \%$ action potential duration $\left(\mathrm{APD}_{90}\right)$ was measured as the average $90 \%$ repolarization time for MAP. The APD alternans was recorded under regular pacing at a reduced length from $120 \mathrm{~ms}$ to $100 \mathrm{~ms}$ in 10 -ms steps and then from $100 \mathrm{~ms}$ to 30 $\mathrm{ms}$ in 5-ms steps. The maximal pacing cycle length-induced electric alternans was defined as the electric alternans threshold. Burst pacing with 2-ms pulses at $50 \mathrm{~Hz}$ and a 2-s burst duration was used to determine ventricular tachycardia (VT) inducibility. VT was considered to have occurred when at least 4 consecutive ventricular waveforms were observed.

\section{Statistical Analysis}

The data analyses were performed using SPSS 19.0. Data were presented as median. Differences between groups were assessed by non-parametric tests: Kruskal-Wallis test. Categorical data were expressed as percentages, and Fisher's exact test was used for statistical analysis. The survival data were analysed with the KaplanMeier plot and were compared with the log-rank test. $p$ values $<0.05$ were considered to be statistically significant.

\section{Results}

\section{DAP Reduced Myocardial I/R Injury in Mice}

As shown in Figure $2 b$ and $c$, there was no significant difference in the risk area of the LV between the untreated and DAP-treated groups $24 \mathrm{~h}$ after reperfusion. However, the infarct size of the risk area was significantly reduced in the DAP-treated $(2.5,5,10$, or $20 \mathrm{mg} / \mathrm{kg})$ groups compared with the untreated group $24 \mathrm{~h}$ after reperfusion (Fig. 2b, d). Additionally, no further reduction in infarct size of the risk area was observed in the $20 \mathrm{mg} / \mathrm{kg} \mathrm{I} / \mathrm{R}$ group compared with the $10 \mathrm{mg} / \mathrm{kg} \mathrm{I/R}$ group (Fig. 2b, d). Similarly, pretreatment with $\operatorname{DAP}(2.5,5,10$, or $20 \mathrm{mg} /$ $\mathrm{kg}$ ) markedly reduced the levels of $\mathrm{CK}-\mathrm{MB}$ and $\mathrm{LDH}$ $24 \mathrm{~h}$ after reperfusion (Fig. 2e, f), but no significant difference in the levels of CK-MB and $\mathrm{LDH}$ was observed between the 10 and $20 \mathrm{mg} / \mathrm{kg} \mathrm{I/R}$ groups (Fig. 2e, f).

\section{DAP Increased Cardiac Function and Improved Survival Rate}

As shown in Figure $3 \mathrm{a}-\mathrm{c}$, DAP $(10 \mathrm{mg} / \mathrm{kg})$ did not exert a negative inotropic effect under sham conditions. After I/R, compared with the sham group, there were obvious reductions in EF and FS in the I/R group (Fig. 3a-c). Conversely, the DAP (10 $\mathrm{mg} / \mathrm{kg}$ )-treated group showed significant increases in EF and FS compared to the untreated group after I/R (Fig. 3a-c). However, the EF and FS observed $24 \mathrm{~h}$ after reperfusion were similar to those observed 7 or 28 days after I/R in the DAP (10 mg/kg)treated group (Fig. $3 \mathrm{a}-\mathrm{c}$ ). In addition, the minimum and maximum rates of pressure increase $(\mathrm{dp} / \mathrm{dt}$ min and $\mathrm{dp} /$ dt max, respectively) were decreased 28 days after I/R compared with those of the sham group, whereas DAP $(10 \mathrm{mg} / \mathrm{kg})$ reversed the $\mathrm{I} / \mathrm{R}$-induced reduction in $\mathrm{dp} / \mathrm{dt}$ min and dp/dt max (Fig. 3d, e). Finally, DAP (10 mg/kg) improved the 28-day survival rate after myocardial I/R (88.2 vs. $58.8 \%, p<0.05$; Fig. $3 f$ ).

\section{DAP Attenuated the Inflammatory Response, Oxidative Stress, and Cardiomyocyte Apoptosis in Mice}

As shown in Figure $4 \mathrm{a}$ and $\mathrm{b}$, the levels of TNF- $\alpha$ and IL-6 were increased $24 \mathrm{~h}$ after reperfusion compared with those in the sham group, while pretreatment with DAP $(10 \mathrm{mg} / \mathrm{kg})$ markedly decreased the level of inflammatory cytokines (Fig. 4a, b). Western blot analysis indicated that pretreatment with DAP $(10 \mathrm{mg} / \mathrm{kg})$ markedly inhibited the I/R-induced expression of ICAM-1 and VCAM-1 (Fig. 4c-e). Immunofluorescence staining 


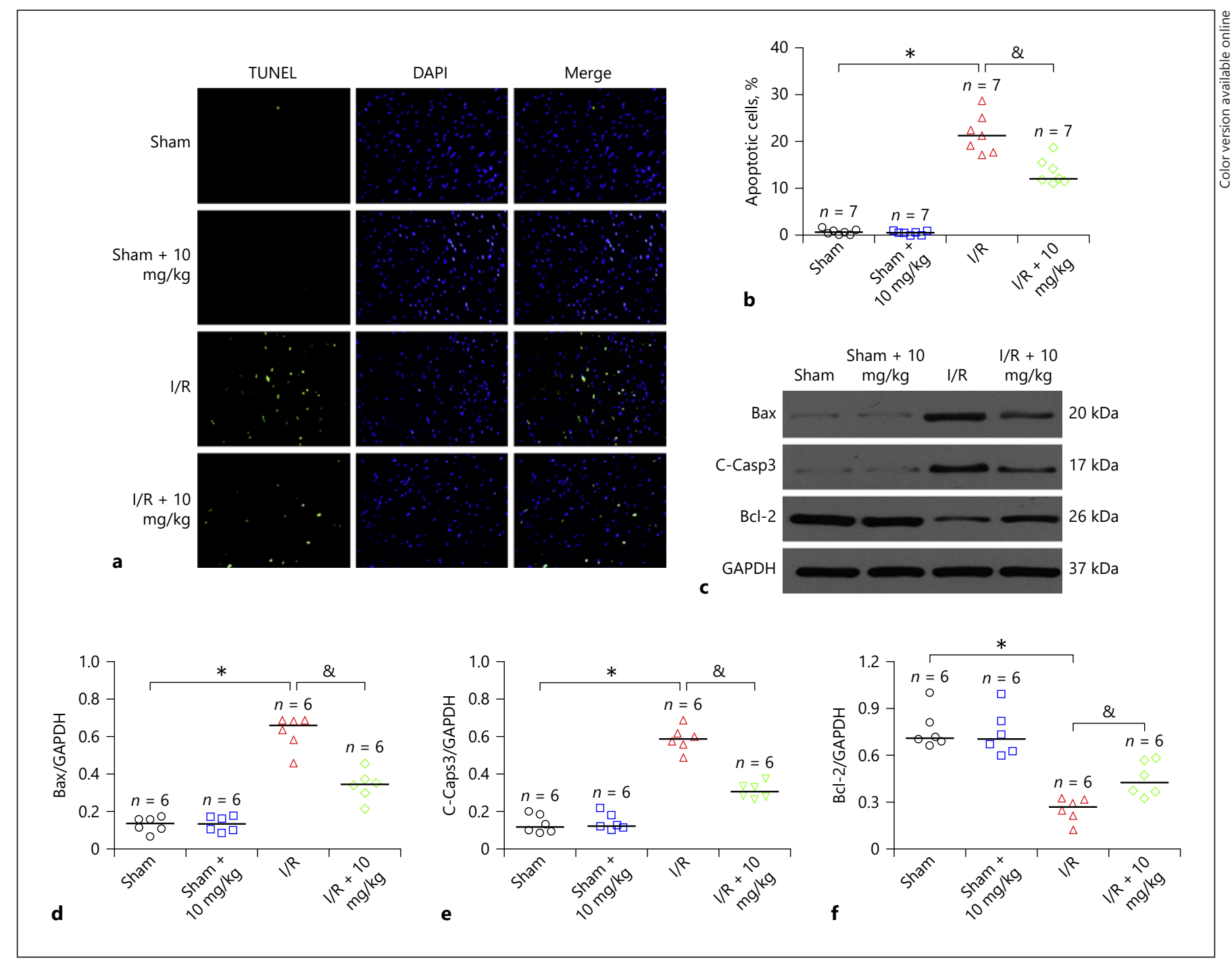

Fig. 6. a Representative TUNEL staining in mouse hearts. Apoptotic nuclei are labelled green, and total nuclei are labelled blue. $\mathbf{b}$ Scatter dot plots quantifying the percentage of positive nuclei $(n=7)$. Representative Western blots (c) and scatter dot plots quantifying Bax, cleaved caspase-3, and Bcl-2 expression in mouse hearts (d-f) $(n=6) .{ }^{*} p<0.05$ versus the sham group; ${ }^{\star} p<0.05$ versus the I/R group. TUNEL, Terminal deoxynucleotidyl transferase-mediated dUTP nick-end labelling; I/R, ischaemia/reperfusion.

analysis showed that DAP (10 mg/kg) pretreatment significantly decreased the number of neutrophils after I/R (Fig. 4f, g). I/R also significantly increased the level of MDA and decreased the activity of SOD compared to the sham group (Fig. 5), but DAP (10 mg/kg) pretreatment reversed these alterations (Fig. 5).

TUNEL staining showed that the number of apoptotic myocardial cells was significantly increased in the I/R group compared with the sham group (Fig. 6a, b). Conversely, pretreatment with DAP $(10 \mathrm{mg} / \mathrm{kg})$ significantly decreased cardiomyocyte apoptosis (Fig. 6a, b). Western blot analysis showed that pretreatment with DAP (10 mg/ $\mathrm{kg}$ ) also decreased the expression of Bax and cleaved caspase- 3 and increased the expression of Bcl-2 induced by I/R (Fig. 6c-f).

\section{DAP Decreased Susceptibility to Ventricular Arrhythmia}

As shown in Figure $7 \mathrm{~b}$ and $\mathrm{c}$, there was no difference in the RR interval or PR interval between the sham and I/R groups. The QRS and QTc intervals were prolonged after I/R compared with those of the sham group, but pretreat- 


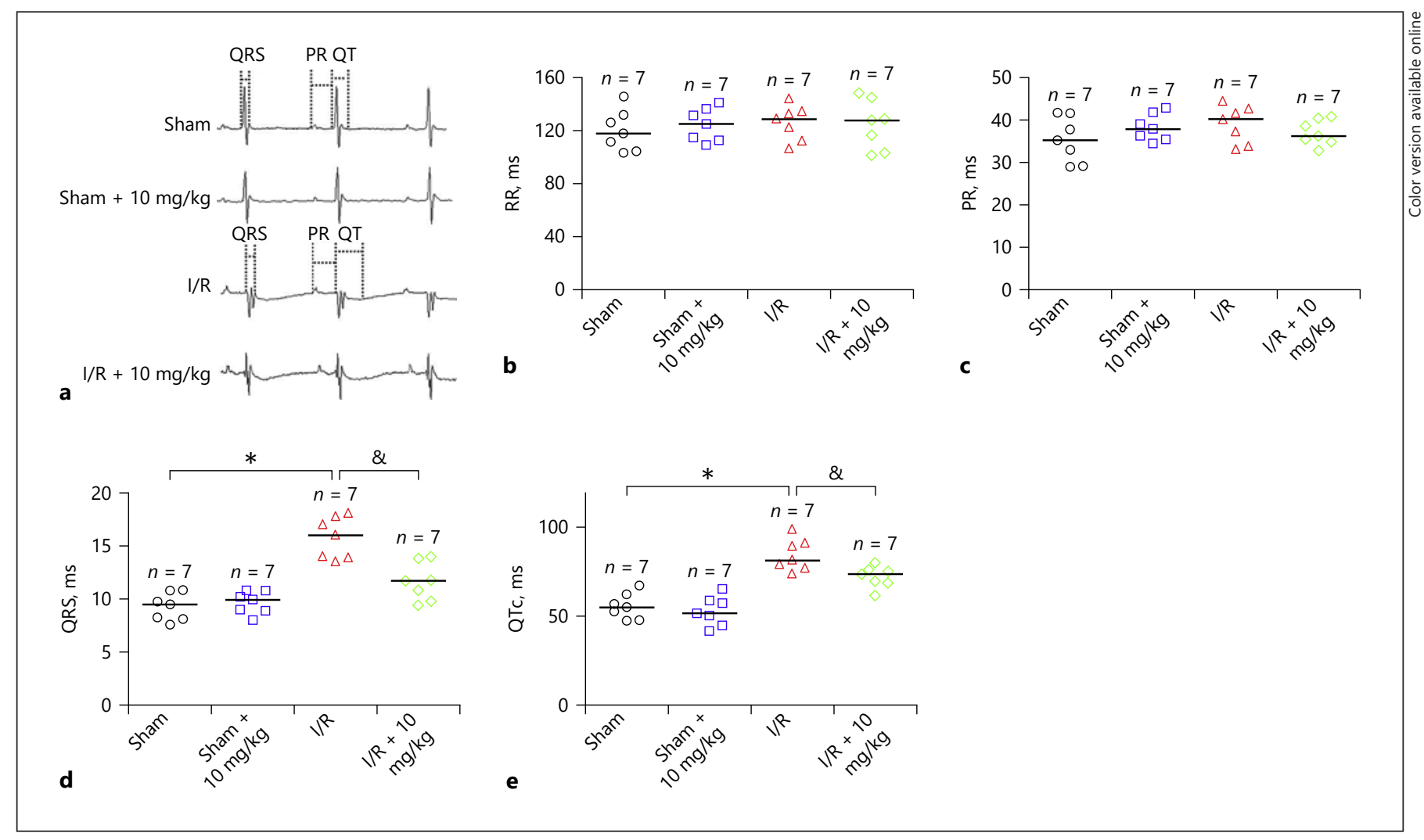

Fig. 7. Representative images of ECG (a) and scatter dot plots quantifying RR, PR, QRS, and QTc interval (b-e) $(n=7) .{ }^{*} p<0.05$ versus the sham group; ${ }^{*} p<0.05$ versus the I/R group. I/R, ischaemia/reperfusion.

ment with DAP $(10 \mathrm{mg} / \mathrm{kg})$ significantly shortened the QRS and QTc intervals (Fig. 7d, e). Meanwhile, I/R markedly prolonged the $\mathrm{APD}_{90}$, decreased the threshold of electric alternans, and increased the VT inducibility rate (Fig. 8). In contrast, pretreatment with DAP $(10 \mathrm{mg} / \mathrm{kg})$ inhibited the changes in the $\mathrm{APD}_{90}$ and threshold of electric alternans and decreased the VT inducibility rate (Fig. 8).

\section{DAP Inhibited the TLR4/NF-Kb Signalling Pathways in Mice}

As shown in Figure 9, I/R markedly increased the expression of TLR4, MyD88, and p-NF- $\kappa \mathrm{B} / \mathrm{P} 65$ compared with that in the sham group. However, pretreatment with DAP $(10 \mathrm{mg} / \mathrm{kg})$ significantly inhibited the expression of TLR4, MyD88, and p-NF-kB/P65 (Fig. 9).

\section{DAP Attenuated H/R-Induced Injury, Apoptosis,} Inflammatory Cytokine Expression, and Oxidative Stress through the TLR4/NF-Kb Signalling Pathway

As shown in Figures $10 \mathrm{a}-\mathrm{c}$, compared with the control, H/R markedly decreased cell viability and promoted cell apoptosis. Pretreatment with DAP $(5,10,20$, or 40 $\mu \mathrm{M})$ increased cell viability and inhibited cell apoptosis (Fig. 10a-c). These changes were similar between the $20 \mu \mathrm{M}$ and $40 \mu \mathrm{M} \mathrm{H} / \mathrm{R}$ groups (Fig. 10a-c). Additionally, the mRNA levels of TNF- $\alpha$ and IL- 6 were significantly downregulated in the $20 \mu \mathrm{M} \mathrm{H} / \mathrm{R}$ group compared to the H/R group (Fig. 10d, e). Furthermore, pretreatment with DAP $(20 \mu \mathrm{M})$ dramatically reduced the levels of MDA and increased the activity of SOD after H/R (Fig. 10f, g). Finally, Western blot analysis showed that DAP $(20 \mu \mathrm{M})$ pretreatment significantly inhibited the expression of TLR4, MyD88, and p-NF- $\mathrm{kB} / \mathrm{P} 65$ in cells subjected to H/R (Fig. 11).

\section{Discussion}

Coumarins comprise a large class of benzopyrone substances obtained from both natural products and synthetic methods. Coumarins are known to possess a variety of pharmaceutical properties and may have promising pro- 


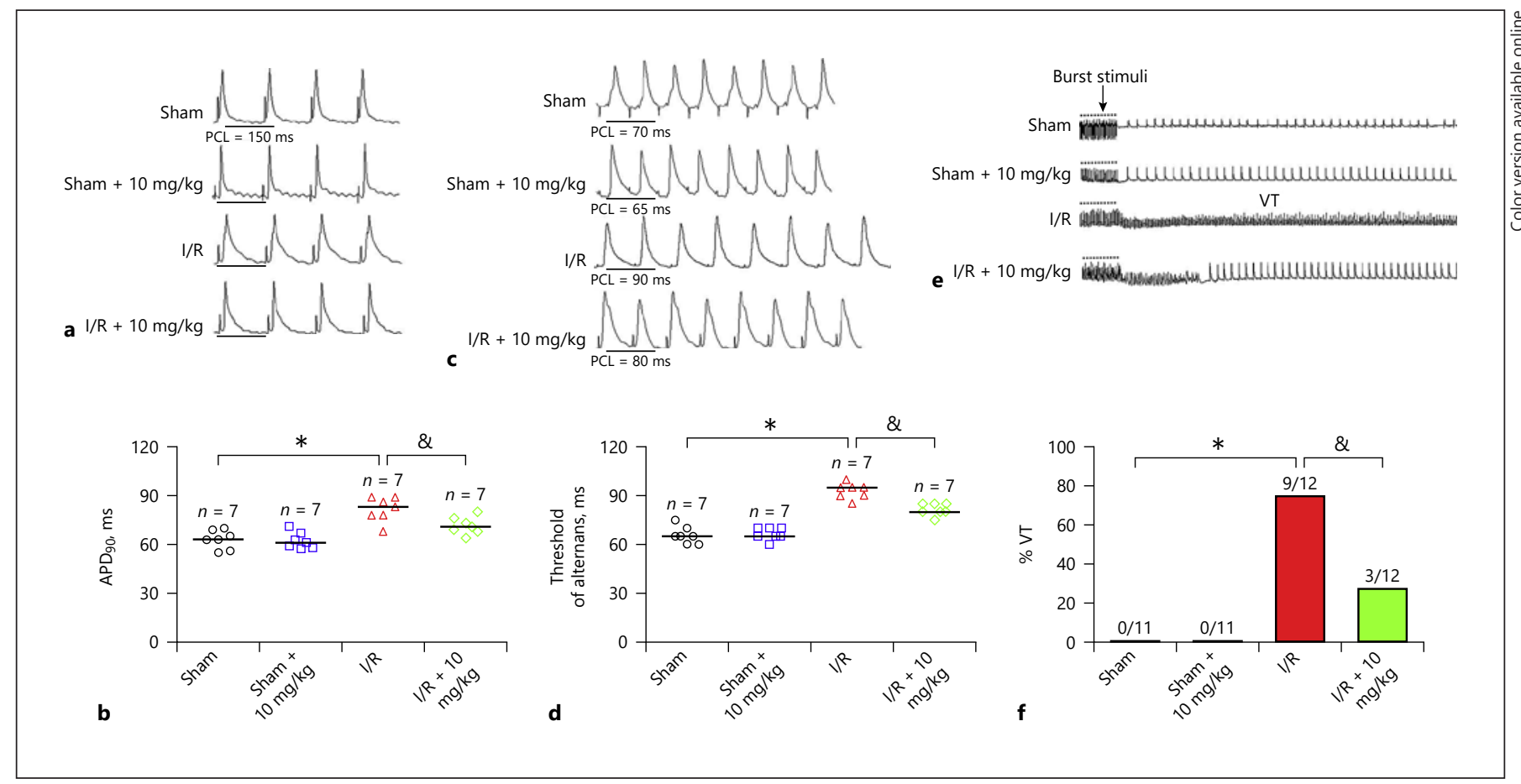

Fig. 8. Representative MAP (a) and scatter dot plots quantifying $\mathrm{APD}_{90}(\mathbf{b})(n=7)$. Representative electric alternans (c) and scatter dot plots quantifying electric alternans thresholds $(\mathbf{d})(n=7)$. Representative VT $(\mathbf{e})$ and bar graph quantifying the VT inducibility rate $(\mathbf{f})$ $(n=11-12) .{ }^{*} p<0.05$ versus the sham group; ${ }^{*} p<0.05$ versus the I/R group. $\mathrm{APD}_{90}, 90 \%$ action potential duration; VT, ventricular tachycardia; MAP, monophasic action potential; I/R, ischaemia/reperfusion.

Fig. 9. Representative Western blots of mouse tissues (a) and scatter dot plots quantifying TLR4, MyD88, and p-NF- $\mathrm{B} /$ $\mathrm{P} 65$ (b-d) $(n=6) .{ }^{*} p<0.05$ versus the sham group; ${ }^{\&} p<0.05$ versus the I/R group. I/R, ischaemia/reperfusion.

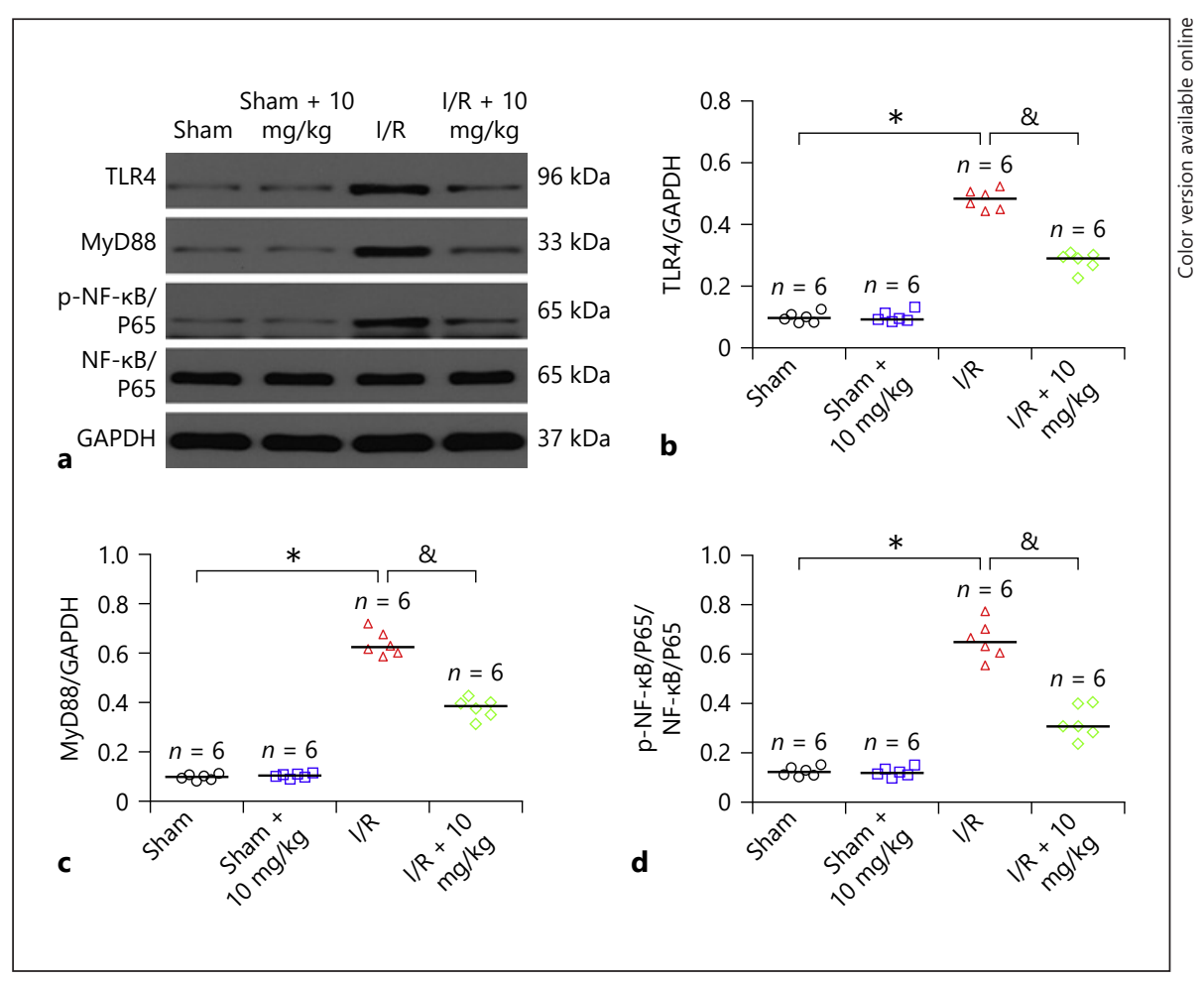


Fig. 10. a Scatter dot plots quantifying the viability of H9c2 cells $(n=7)$. Representative flow cytometry (b) and scatter dot plots quantifying the apoptosis rate of H9c2 cells $(\mathbf{c})(n=7)$. d, e Scatter dot plots quantifying the mRNA levels of TNF- $\alpha$ and IL-6 in H9c2 cells $(n=6)$. $\mathbf{f}, \mathbf{g}$ Scatter dot plots quantifying level of MDA and activity of SOD in H9c2 cells $(n=6) .{ }^{*} p<0.05$ versus the control group; ${ }^{\&} p<0.05$ versus the $\mathrm{H} / \mathrm{R}$ group; ${ }^{\#} p>0.05$ between the $20 \mu \mathrm{M}$ and $40 \mu \mathrm{M}$ DAP treatment groups. DAP, daphnetin; MDA, malondialdehyde; SOD, superoxide dismutase; IL-6, interleukin-6; TNF- $\alpha$, tumour necrosis factor-alpha; H/R, hypoxia/reoxygenation; FITC, fluorescein isothiocyanate.

Daphnetin Decreases Myocardial I/R Injury and Susceptibility to Arrhythmia
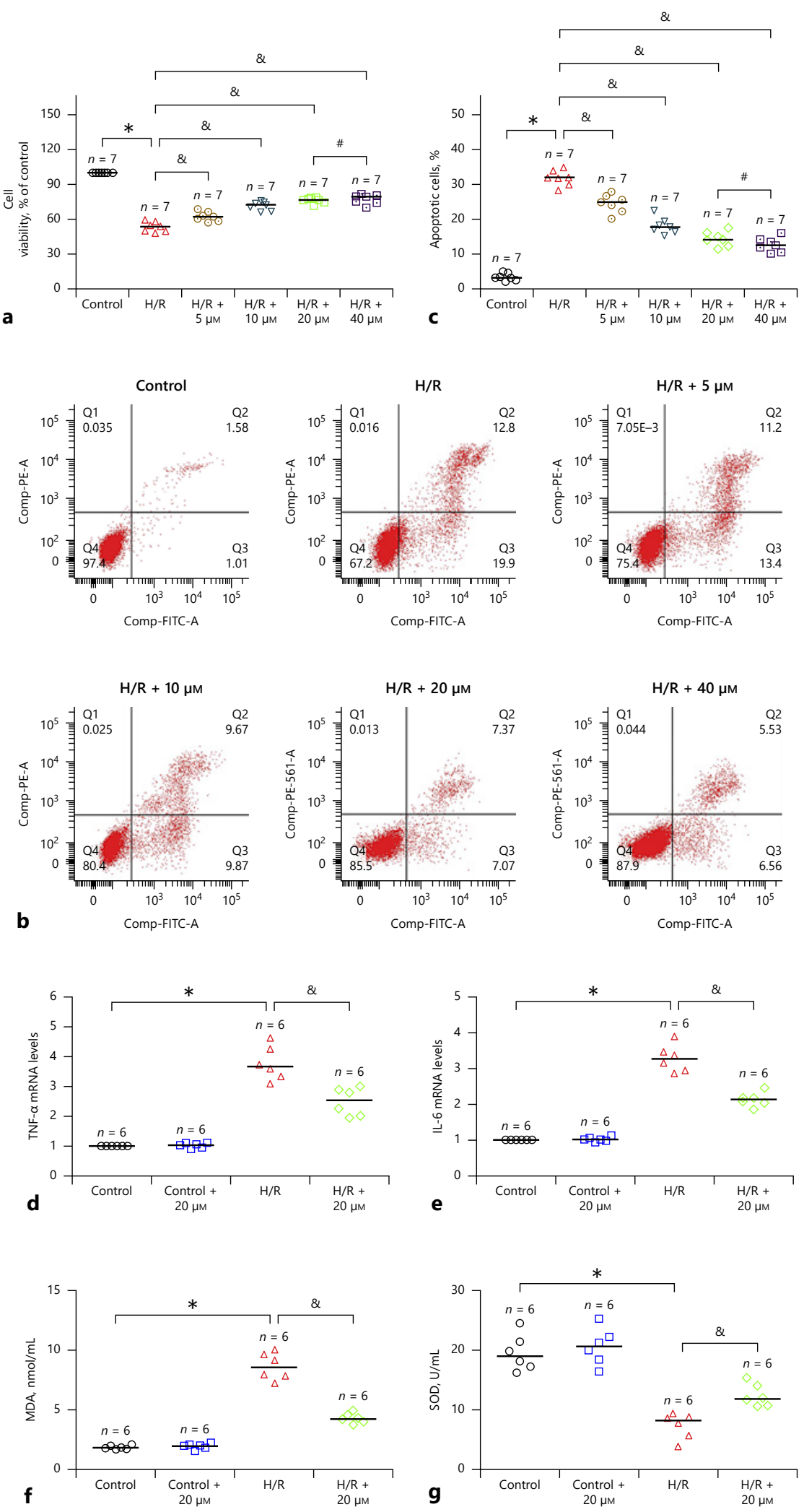
Fig. 11. Representative Western blots of H9c2 cells (a) and scatter dot plots quantifying TLR4, MyD88, and p-NF- $\kappa \mathrm{B} / \mathrm{P} 65$ (bd) $(n=6) .{ }^{*} p<0.05$ versus the control group; ${ }^{\&} p<0.05$ versus the $\mathrm{H} / \mathrm{R}$ group. $\mathrm{H} / \mathrm{R}$, hypoxia/reoxygenation.

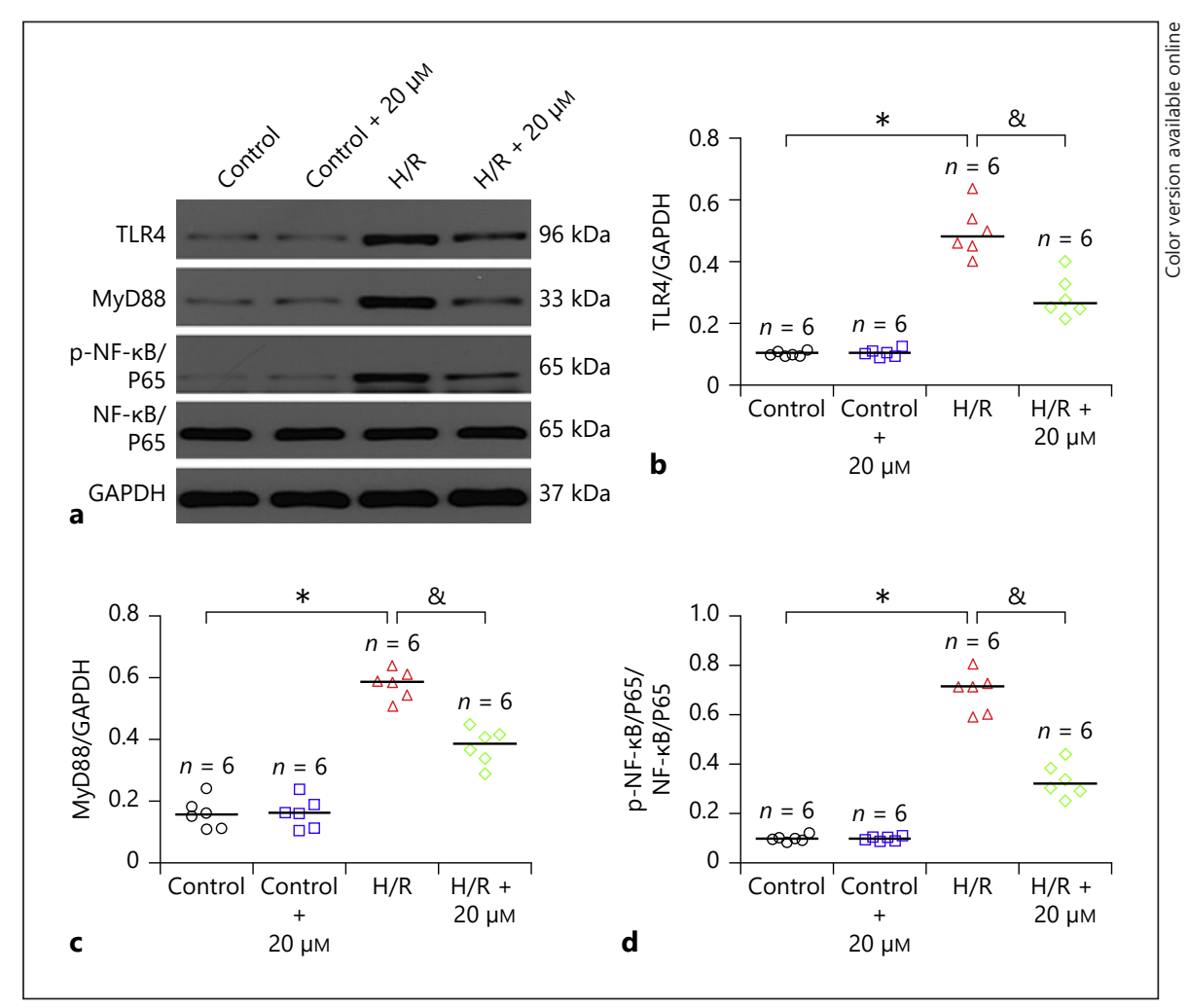

tective effects on I/R. For example, aesculetin or umbelliferone, which have structures similar to that of DAP, have been reported to attenuate myocardial I/R injury $[16,17]$. DAP is extracted from the plants of the D. koreana Nakai and belongs to the coumarin family. In this study, the cardioprotective effects of DAP were examined in a myocardial I/R model and an $\mathrm{H} / \mathrm{R}$ model. The results showed that DAP preconditioning reduced the infarct size and improved cardiac function. However, treatment with DAP after reperfusion did not further improve cardiac function. DAP preconditioning markedly inhibited apoptosis, inflammatory responses, and oxidative stress and decreased susceptibility to ventricular arrhythmia. Furthermore, DAP preconditioning significantly suppressed the TLR4/MyD88/NF- $\kappa B$ signalling pathway.

Previous studies have indicated that ROS play a double-edged role in cardioprotection [18]. A small amount of ROS may contribute to protection [19]. However, the formation of excessive ROS can lead to the denaturation of proteins, lipid peroxidation, and DNA damage. I/R can cause an imbalance in oxidants and antioxidants and result in oxidative stress [20]. The generation of excessive ROS contributes to irreversible myocardial injury [19, 21]. MDA is a marker of lipid peroxidation, and SOD is an endogenous antioxidase. Their levels may be related to the defence capacity against oxidative injuries. In the present study, preconditioning with DAP markedly increased the SOD activity and decreased the MDA levels.

The inflammatory response is a prerequisite for tissue repair in response to tissue injury [22]. Uncontrolled inflammatory responses, however, counter these beneficial effects and promote I/R-induced tissue injury [23]. Previous studies have shown that myocardial ischaemia promotes chemokine release, adhesion molecule expression, and inflammatory cell infiltration [24-26]. Additionally, these recruited inflammatory cells further mediate the release of pro-inflammatory cytokines, proteases, and ROS, which form a positive feedback loop and exacerbate tissue injury [27]. Some studies have demonstrated that inhibition of the inflammatory response is beneficial for reducing I/R injury [28-30]. Consistent with previous studies, the present study also demonstrated that I/R markedly increased the inflammatory response. However, preconditioning with DAP significantly decreased the levels of pro-inflammatory cytokines, expression of adhesion molecules, and infiltration of inflammatory cells.

Apoptosis has been demonstrated to contribute to myocardial I/R-induced injury [31]. Bcl-2 family proteins are significant regulators of apoptosis and are divided into pro-apoptotic (Bax, Bak) and anti-apoptotic (Bcl-2, 
$\mathrm{Bcl}-\mathrm{xL})$ proteins $[32,33]$. Thus, the downregulation of Bax expression and the upregulation of Bcl-2 expression may attenuate myocardial apoptosis $[34,35]$. The present study showed that DAP preconditioning markedly decreased I/R-induced cardiomyocyte apoptosis. Moreover, Western blot analysis showed that DAP preconditioning inhibited the protein expression of Bax and cleaved caspase- 3 and upregulated Bcl-2 expression.

Previous studies showed that cardiac ischaemia can induce the ATP-sensitive K current, and shorten the APD and QT intervals [36]. However, the APD and QT intervals were prolonged and exceeded normal levels during the reperfusion phase [37]. Chen et al. [38] reported that $\mathrm{I} / \mathrm{R}$ may inhibit the delayed rectifier potassium $(\mathrm{IKr})$ channel and prolong the APD and QT interval. In I/R, excessive $\mathrm{Ca}^{2+}$ entry may be related to the $\mathrm{Na}^{+} / \mathrm{Ca}^{2+}$ exchanger (NCX), and ablation of the NCX may protect against myocardial I/R injury [39]. Additionally, inhibition of the NCX may reduce the QT interval and arrhythmia $[40,41]$. Previous studies showed that TLR4 activation may increase the expression of NCX, reduce the transient outward potassium current (Ito), and prolong the APD and QT interval $[42,43]$. Moreover, inhibition of or a deficiency in TLR4 also markedly inhibits inflammatory responses and ROS and reduces infarct size $[44,45]$. MyD88 and NF- $\kappa B$ are important downstream effectors of TLR4. A previous study showed that NF- $\kappa B$ can regulate the transient outward potassium current [46]. Meanwhile, recent studies suggested that the TLR4/NF- $\kappa B$ signalling pathway is involved in mediating myocardial I/R injury and susceptibility to arrhythmia $[14,47]$. Thus, the TLR4/NF- $\kappa B$ signalling pathway may play an important role in I/R injury and arrhythmia. The present study showed that DAP preconditioning markedly shortened the APD and QTc intervals, increased the threshold of electric alternans, and reduced the arrhythmia inducibility rate after myocardial I/R. Western blot analysis showed that DAP preconditioning significantly inhibited the expression of TLR4, MyD88, and p-NF- $\mathrm{KB} / \mathrm{P} 65$ in mice subjected to I/R and cells subjected to $H / R$. Thus, these results suggest that DAP preconditioning reduced myocardial I/R injury and susceptibility to ventricular arrhythmia, probably through regulation of the TLR4/MyD88/NF- $\kappa B$ signalling pathway.

This work also has some limitations. First, although DAP at a dose of 40 or $80 \mathrm{mg} / \mathrm{kg}$ may reduce platelet adhesion and inhibit platelet aggregation [12], it is unknown whether DAP at these doses exerts anticoagulation effects in this study. Second, this study showed that DAP preconditioning provides a cardioprotective effect. Howev-

Daphnetin Decreases Myocardial I/R

Injury and Susceptibility to Arrhythmia

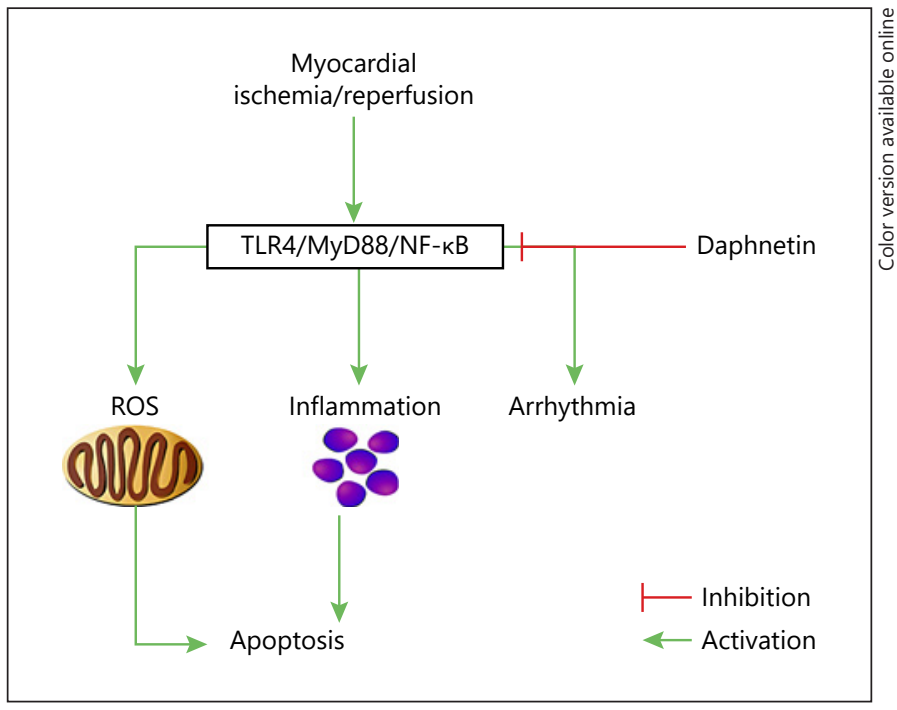

Fig. 12. Schematic diagram of the protective mechanism of DAP against I/R injury and ventricular arrhythmia. DAP, daphnetin; $\mathrm{I} / \mathrm{R}$, ischaemia/reperfusion.

er, the effects of DAP as a postconditioning treatment at $24 \mathrm{~h}$ should be investigated since the therapeutic time window of cardioprotection is truly important for treating $\mathrm{I} / \mathrm{R}$ injury. Third, this study indicated that DAP preconditioning changes the QT interval and APD and reduces the susceptibility to ventricular arrhythmia, and the underlying mechanisms may be related to the regulation of ion channels, such as K+ channels and the NCX. Therefore, these problems should be further researched in future studies.

In conclusion, the present study demonstrated that DAP preconditioning protects the heart against I/ $\mathrm{R}$ injury and reduces susceptibility to ventricular arrhythmia. Furthermore, the potential mechanism of the cardioprotective effect of DAP preconditioning may be associated with the TLR4/MyD88/NF- $\kappa B$ signalling pathway (Fig. 12). However, treatment with DAP after reperfusion may not provide any further improvement. Thus, DAP may have potential benefits for the prevention of I/R injury related to predictable I/R stress, such as heart transplantation and cardiac surgery with aortic clamping.

\section{Statement of Ethics}

All animal and study protocols were approved by the Ethics Committee of Renmin Hospital of Wuhan University (IACUC No. 20171224) and conducted in accordance with the Guide for the Care and Use of Laboratory Animals published by the US National Institutes of Health (Publication No. 85-23, revised 1996). 


\section{Conflict of Interest Statement}

The authors declare that they have no conflict of interest.

\section{Funding Sources}

This work was supported by the Central Government Guides Local Science and Technology Development Special Projects (No. 2019ZYYD062).

\section{Author Contributions}

Fan Yang and Xiaobo Jiang carried out the experiments and drafted the manuscript. Wei Shuai and Dajun Quan carried out the experiments. Guangji Wang, Hongyi Cao, and Lijun Zhang were responsible for data integrity and analysis. Xuejun Jiang designed the study and reviewed the manuscript.

\section{References}

1 Arnett DK, Blumenthal RS, Albert MA, Buroker AB, Goldberger ZD, Hahn EJ, et al. ACC/ AHA guideline on the primary prevention of cardiovascular disease: a report of the American College of Cardiology/American Heart Association Task Force on clinical practice guidelines. Circulation. 2019 Sept;140(11): e596-e646.

2 Appleyard RF, Cohn LH. Myocardial stunning and reperfusion injury in cardiac surgery. J Card Surg. 1993 Mar;8(2 Suppl):31624.

3 Weisel RD. Myocardial stunning after coronary bypass surgery. J Card Surg. 1993 Mar; 8(2 Suppl):242-4.

4 Yellon DM, Hausenloy DJ. Myocardial reperfusion injury. N Engl J Med. 2007 Sept; 357(11):1121-35.

5 Eltzschig HK, Eckle T. Ischemia and reperfusion: from mechanism to translation. Nat Med. 2011 Nov;17(11):1391-401.

6 González-Montero J, Brito R, Gajardo AI, Rodrigo R. Myocardial reperfusion injury and oxidative stress: therapeutic opportunities. World J Cardiol. 2018 Sept;10(9):74-86.

7 Wallert M, Ziegler M, Wang X, Maluenda A, $\mathrm{Xu}$ X, Yap ML, et al. $\alpha$-Tocopherol preserves cardiac function by reducing oxidative stress and inflammation in ischemia/reperfusion injury. Redox Biol. 2019 Sept;26:101292.

8 Tu CC, Wan BY, Zeng Y. STIM2 knockdown protects against ischemia/reperfusion injury through reducing mitochondrial calcium overload and preserving mitochondrial function. Life Sci. 2020 Apr;247:116560.

9 Fylaktakidou KC, Hadjipavlou-Litina DJ, Litinas KE, Nicolaides DN. Natural and synthetic coumarin derivatives with anti-inflammatory/ antioxidant activities. Curr Pharm Des. 2004;10(30):3813-33.

10 Yu W, Wang H, Ying H, Yu Y, Chen D, Ge W, et al. Daphnetin attenuates microglial activation and proinflammatory factor production via multiple signaling pathways. Int Immunopharmacol. 2014 Jul;21(1):1-9.

11 Vinayagam R, Xu B. 7, 8-Dihydroxycoumarin (daphnetin) protects INS-1 pancreatic $\beta$-cells against streptozotoc- induced apoptosis. Phytomedicine. 2017 Jan;24:119-26.

12 Qu SY, Jiang XL, Zhao XH, Pan DB, Wang $\mathrm{XR}$, Chen YL, et al. [Antithrombotic effect of daphnetin in the rat]. Yao Xue Xue Bao. 1986 Jul;21(7):498-501.

13 Liu J, Chen Q, Jian Z, Xiong X, Shao L, Jin T, et al. Daphnetin protects against cerebral ischemia/reperfusion injury in mice via inhibition of TLR4/NF- $\mathrm{kB}$ signaling pathway. Biomed Res Int. 2016;2016:2816056.

14 Jiang X, Kong B, Shuai W, Shen C, Yang F, Fu $\mathrm{H}$, et al. Loss of MD1 exacerbates myocardial ischemia/reperfusion injury and susceptibility to ventricular arrhythmia. Eur J Pharmacol. 2019 Feb;844:79-86.

15 Ji YX, Zhang P, Zhang XJ, Zhao YC, Deng $\mathrm{KQ}$, Jiang $\mathrm{X}$, et al. The ubiquitin E3 ligase TRAF6 exacerbates pathological cardiac hypertrophy via TAK1-dependent signalling. Nat Commun. 2016 Jun; 7:11267.

16 He Y, Li C, Ma Q, Chen S. Esculetin inhibits oxidative stress and apoptosis in H9c2 cardiomyocytes following hypoxia/reoxygenation injury. Biochem Biophys Res Commun. 2018 Jun;501(1):139-44.

17 Luo H, Fan Z, Xiang D, Jiang Z, Zhang W, Gao L, et al. The protective effect of umbelliferone ameliorates myocardial injury following ischemia: reperfusion in the rat through suppression NLRP3 inflammasome and upregulating the PPAR- $\gamma$. Mol Med Rep. 2018 Feb;17(2):3404-10.

18 Tullio F, Angotti C, Perrelli MG, Penna C, Pagliaro P. Redox balance and cardioprotection. Basic Res Cardiol. 2013 Nov; 108(6):392.

19 Heusch G. Molecular basis of cardioprotection: signal transduction in ischemic pre-, post-, and remote conditioning. Circ Res. 2015 Feb;116(4):674-99.

20 Goswami SK, Maulik N, Das DK. Ischemiareperfusion and cardioprotection: a delicate balance between reactive oxygen species generation and redox homeostasis. Ann Med. 2007;39(4):275-89.

21 Murphy E, Steenbergen C. Mechanisms underlying acute protection from cardiac ischemia-reperfusion injury. Physiol Rev. 2008 Apr;88(2):581-609.

22 Timmers L, Pasterkamp G, de Hoog VC, Arslan F, Appelman Y, de Kleijn DP. The innate immune response in reperfused myocardium. Cardiovasc Res. 2012 May;94(2):276-83.

23 Nathan C, Ding A. Nonresolving inflammation. Cell. 2010 Mar; 140(6):871-82.
24 Frangogiannis NG, Smith CW, Entman ML. The inflammatory response in myocardial infarction. Cardiovasc Res. 2002 Jan;53(1):31-47.

25 Frangogiannis NG, Entman ML. Chemokines in myocardial ischemia. Trends Cardiovasc Med. 2005 Jul;15(5):163-9.

26 Yu LM, Dong X, Xue XD, Zhang J, Li Z, Wu HJ, et al. Protection of the myocardium against ischemia/reperfusion injury by punicalagin through an SIRT1-NRF-2-HO-1-dependent mechanism. Chem Biol Interact. 2019 Jun;306:152-62.

27 Vinten-Johansen J. Involvement of neutrophils in the pathogenesis of lethal myocardial reperfusion injury. Cardiovasc Res. 2004 Feb; 61(3):481-97.

28 Maekawa N, Wada H, Kanda T, Niwa T, Yamada $\mathrm{Y}$, Saito $\mathrm{K}$, et al. Improved myocardial ischemia/reperfusion injury in mice lacking tumor necrosis factor-alpha. J Am Coll Cardiol. 2002 Apr;39(7):1229-35.

29 Jong WM, Ten Cate H, Linnenbank AC, de Boer OJ, Reitsma PH, de Winter RJ, et al. Reduced acute myocardial ischemia-reperfusion injury in IL-6-deficient mice employing a closed-chest model. Inflamm Res. 2016 Jun; 65(6):489-99.

30 Ampofo E, Berg JJ, Menger MD, Laschke MW. Maslinic acid alleviates ischemia/reperfusion-induced inflammation by downregulation of NFKB-mediated adhesion molecule expression. Sci Rep. 2019 Apr;9(1):6119.

31 Gottlieb RA, Engler RL. Apoptosis in myocardial ischemia-reperfusion. Ann N Y Acad Sci. 1999 Jun;874:412-26.

32 Burlacu A. Regulation of apoptosis by Bcl-2 family proteins. J Cell Mol Med. 2003 JulSept;7(3):249-57.

33 Youle RJ, Strasser A. The BCL-2 protein family: opposing activities that mediate cell death. Nat Rev Mol Cell Biol. 2008 Jan;9(1):47-59.

34 Yuan Y, Wang YY, Liu X, Luo B, Zhang L, Zheng F, et al. KPC1 alleviates hypoxia/reoxygenation-induced apoptosis in rat cardiomyocyte cells though BAX degradation. J Cell Physiol. 2019 Dec;234(12):22921-34.

35 Chen Z, Chua CC, Ho YS, Hamdy RC, Chua $\mathrm{BH}$. Overexpression of $\mathrm{Bcl}-2$ attenuates apoptosis and protects against myocardial $\mathrm{I} / \mathrm{R}$ injury in transgenic mice. Am J Physiol Heart Circ Physiol. 2001 May;280(5):H2313-20. 
36 Akar JG, Akar FG. Regulation of ion channels and arrhythmias in the ischemic heart. J Electrocardiol. 2007 Nov-Dec;40(6 Suppl):S3741.

37 Ueda N, Zipes DP, Wu J. Coronary occlusion and reperfusion promote early afterdepolarizations and ventricular tachycardia in a canine tissue model of type 3 long QT syndrome. Am J Physiol Heart Circ Physiol. 2006 Feb;290(2):H607-12.

38 Chen Y, Yin C, Yang Y, Fan Z, Shang J, Tan $W$. Inhibition of rapid delayed rectififier potassium current (IKr) by ischemia/reperfusion and its recovery by vitamin $\mathrm{E}$ in ventricular myocytes. J Electrocardiol. 2017 Jul-Aug; 50(4):437-43

39 Imahashi K, Pott C, Goldhaber JI, Steenbergen C, Philipson KD, Murphy E. Cardiac-specific ablation of the $\mathrm{Na}+-\mathrm{Ca} 2+$ exchanger confers protection against ischemia/reperfusion injury. Circ Res. 2005 Oct;97(9):916-21.
40 Milberg P, Pott C, Fink M, Frommeyer G, Matsuda T, Baba A, et al. Inhibition of the $\mathrm{Na}+/ \mathrm{Ca} 2+$ exchanger suppresses torsades de pointes in an intact heart model of long QT syndrome-2 and long QT syndrome-3. Heart Rhythm. 2008 Oct;5(10):1444-52.

41 Sventzouri S, Nanas I, Vakrou S, Kapelios C, Sousonis V, Sfakianaki T, et al. Pharmacologic inhibition of the mitochondrial $\mathrm{Na}+/ \mathrm{Ca} 2+$ exchanger protects against ventricular arrhythmias in a porcine model of ischemia-reperfusion. Hellenic J Cardiol. 2018 Jul-Aug; 59(4):217-22.

42 Peng J, Liu Y, Xiong X, Huang C, Mei Y, Wang Z, et al. Loss of MD1 exacerbates pressure overload-induced left ventricular structural and electrical remodelling. Sci Rep. 2017 Jul;7(1):5116.

43 Monnerat-Cahli G, Alonso H, Gallego M, Alarcón ML, Bassani RA, Casis O, et al. Tolllike receptor 4 activation promotes cardiac arrhythmias by decreasing the transient outward potassium current (Ito) through an IRF3-dependent and MyD88-independent pathway. J Mol Cell Cardiol. 2014 Nov;76: $116-25$.
44 Chong AJ, Shimamoto A, Hampton CR, Takayama H, Spring DJ, Rothnie CL, et al. Toll-like receptor 4 mediates ischemia/reperfusion injury of the heart. J Thorac Cardiovasc Surg. 2004 Aug;128(2):170-9.

45 Oyama J, Blais C Jr, Liu X, Pu M, Kobzik L, Kelly RA, et al. Reduced myocardial ischemiareperfusion injury in toll-like receptor 4-deficient mice. Circulation. 2004 Feb;109(6):7849.

46 Panama BK, Latour-Villamil D, Farman GP, Zhao D, Bolz SS, Kirshenbaum LA, et al. Nuclear factor kappaB downregulates the transient outward potassium current I(to $\mathrm{f}$ ) through control of KChIP2 expression. Circ Res. 2011 Mar;108(5):537-43.

47 Yuan L, Dai X, Fu H, Sui D, Lin L, Yang L, et al. Vaspin protects rats against myocardial ischemia/reperfusion injury (MIRI) through the TLR4/NF- $\mathrm{KB}$ signaling pathway. Eur J Pharmacol. 2018 Sept;835:132-9. 